\title{
IMPLEMENTASI STRATEGI PEMASARAN DENGAN MENGGUNAKAN ANALISIS SWOT DALAM MENINGKATKAN PENJUALAN DAN PENDAPATAN PADA UD. YOGA PUTRA BANGKIT SAMBENG LAMONGAN
}

\author{
Mita Dwi Anggraini ${ }^{1}$ Abid Muhtarom ${ }^{2}$ Nurus Safaatillah $^{3}$ \\ Prodi Manajemen, Fakultas Ekonomi, Universitas Islam Lamongan \\ $\mathrm{Jl}$. Veteran No.53A Lamongan \\ Telp. ( 0322 ) 324706, Faks. ( 0322 ) 324706 \\ nurussafaatillah@gmail.com
}

\begin{abstract}
Abstrak
Penelitian ini menggunakan metode penelitian deskriptif kualitatif di UD. Yoga Putra bangkit dengan judul "Implementasi Strategi Pemasaran dengan Menggunakan Analisis SWOT dalam Meningkatkan Penjualan dan Pendapatan pada UD. Yoga Putra Bangkit Sambeng Lamongan". Tujuan skripsi ini adalah untuk mengetahui apakah strategi pemasaran dengan pendekatan analisa SWOT dapat meningkatkan penjualan dan pendapatan pada UD. Yoga Putra Bangkit. Untuk mengetahui bentuk strategi pemasaran yang dilakukan oleh UD. Yoga Putra Bangkit guna meningkatkan penjualan dan pendapatan yang sesuai dengan perusahaan. Obyek penelitian ini menggunakan metode observasi, wawancara dan dokumentasi. Sedangkan teknik analisa menggunakan teknik analisis SWOT (Strenghts, Weaknesses, Opportunities, Threats). Dari hasil penelitian posisi perusahaan pada saat ini ada pada kuadran 1 merupakan situasi yang sangat menguntungkan. Kesimpulan dari penelitian ini adalah untuk dapat meningkatkan penjualan dan pendapatan pada UD. Yoga Putra Bangkit. Untuk mengetahui bentuk strategi pemasaran yang dilakukan oleh UD. Yoga Putra Bangkit guna meningkatkan penjualan dan pendapatan yang sesuai dengan perusahaan.
\end{abstract}

Kata kuci : Strategi Pemasaran, Analisis SWOT.

\section{PENDAHULUAN}

Menurut Serdamayanti dalam puguh (2016) Strategi adalah rencana yang disatukan, luas dan berintergasi yang menghubungkan keunggulan strategi perusahaan dengan tantangan lingkungan, dirancang untuk memastikan tujuan utama dari perusahaan dapat dicapai melalui pelaksanaan yang tepat oleh organisasi.

Dengan demikian maka pemilik perusahaan atau Owner Home Industi membutuhkan strategi pemasaran untuk mengenalkan produk properti kayu jati pada konsumen, yang berkaitan dengan pendapatan yang akan diperoleh bagi perusahaan yang mereka kelola.

Menurut Uswara dalam Nizar (2016) Bahwa strategi pemasaran merupakan sesuatu yang sangat penting bagi setiap perusahaan, sesuatu yang penting umumnya tidak mudah dirumuskan dan dilaksanakan. Dibutuhkan serangkaian analisis yang mendalam untuk mengurangi ketidak pastian atau resiko yang mungkin 
dihadapi dari masing-masing strategi yang akan diterapkan.

Salah satu strategi yang berhubungan dengan kegiatan pemasaran perusahaan adalah marketing mix strategi yang didefinisikan oleh Kotler dan Keller dalam Nizar (2016) yang menyatakan bahwa : "marketing mix as the set of controllable marketing variables that the firm bleads to produce the response it wants in the target market". Dari definisi diatas dapat diartikan bahwa bauran pemasaran merupakan variabel terkendali yang digabungkan untuk menghasilkan tanggapan yang diharapkan dari pasar sasaran. Dan untuk usaha jasa terdapat 7 unsur marketing mix (marketing mix-7p) yaitu product, price, promotion, place, partisipant, proses, dan physical evidence.

Pada dasarnya tujuan dalam mendirikan perusahaan adalah mencari laba semaksimal mungkin. Keberhasilan suatu perusahaan dalam mencapai tujuan itu sangat dipengaruhi oleh kemampuan perusahaan dalam memasarkan produknya dengan menerapkan strategi pemasaran. Keberhasilan strategi pemasaran dipengaruhi oleh beberapa faktor yaitu riset dan analisa pasar, keputusan tentang produk, penetapan harga, promosi dan distribusi (marketing mix). Menurut Wayan (2017).

Pada sebuah pendapat lain menjelaskan strategi pemasaran harus Jurnal Penelitian Ilmu Manajemen (JPIM) dapat memberikan gambaran yang jelas dan teratur dan tentang apa yang dilakukan oleh perusahaan dan menggunakan setiap kesempatan atau peluang dari beberapa sasaran pasar. Menurut Supariyani dalam Subing (2014).

Perusahaan perlu mengenali kekuatan, kelemahan, peluang dan ancaman dengan menggunakan analisis SWOT. Analisis SWOT sendiri adalah identifikasi berbagai faktor secara sistematis untuk merumuskan strategi perusahaan, analisis ini didasarkan pada logika yang dapat memaksimalkan kekuatan (Strenght) dan peluang (Opportunities), namun secara bersamaan dapat meminimalkan kelemahan (Weakness) dan Ancaman (Threats). (Rangkuti,2016:19).

Menurut Suryatama dalam puguh (2016) analisis SWOT adalah metode perencanaan strategis yang digunakan untuk mengevaluasi kekuatan atau Strengths, kelemahan atau Weaknesses, peluang atau Opportunities, dan ancaman atau Threast dalam suatu proyek atau suatu spekulasi bisnis. Dan dapat diterapkan dengan cara menganalisis dan memilah berbagai hal yang mempengaruhi keempat faktornya.

Menurut Masykur dalam Diyah (2013) menyatakan sebuah pendapatnya bahwa "tujuan perusahaan adalah memaksimumkan penjualan, memaksimumkan laba, dan lain-lain". 
Setiap perusahaan pasti mengharapkan agar hasil penjualan dapat meningkat agar diperoleh laba yang yang cukup besar.

Menurut Nekkels dalam Rohmah (2015) menyebutkan penjualan dengan penjualan tatap muka (personal seling) adalah " interaksi anatar individu. Saling bertatapan muka yang ditujukan untuk menciptakan, memperbaiki, menguasai atau mempertahankan hubungan pertukaran yang saling menguntungkan. Dari pengertian diatas dapat disimpulkan bahwa penjualan yaitu suatu interaksi yang dilakukan oleh pihak penjual ke pembeli untuk menciptakan suatu kondisi pertukaran yang saling menguntungkan.

Menurut Nursandy dalam Wayan (2017) Pendapatan adalah seluruh penerimaan baik berupa uang maupun barang yang berasal dari pihak lain maupun dari hasil industri yang dinilai atas dasar jumlah uang dari harta yang berlalu saat itu.

UD. Yoga Putra Bangkit, sebuah perusahaan yang bergerak dibidang produksi pengolahan kayu jati dalam pembuatan kursi, meja, lemari, pintu, jendela dll. Selain memproduksi UD. Yoga Putra Bangkit juga siap untuk menerima perbaikan barang seperti meja, kursi, lemari, pintu, jendela dll.

Rumusan masalah pada penelitian ini (1) Apakah strategi pemasaran dengan analisis SWOT dapat meningkatkan penjualan dan pendapatan pada UD. Yoga Putra Bangkit? (2) Bagaimana bentuk strategi pemasaran yang dilakukan oleh UD. Yoga Putra Bangkit guna meningkatkan penjualan dan pendapatan yang sesuai dengan perusahaan?

\section{KAJIAN PUSTAKA}

\section{Pemasaran}

Menurut Rangkuti dalam Puguh menjelaskan bahwa pemasaran adalah suatu proses kegiatan yang di pengaruhi oleh berbagai faktor sosial, budaya, politik, ekonomi, dan manajerial.

Menurut Rangkuti

$(2016: 101)$

Pemasaran adalah suatu proses kegiatan yang dipengaruhi oleh berbagai faktor sosial, budaya, politik, ekonomi, dan manajerial.

Unsur-Unsur Utama Pemasaran dapat diklasifikasikan menjadi tiga unsur utama, yaitu:

\section{a. Segmentasi Pasar}

Segmentasi pasar adalah tindakan mengidentifikasi dan membentuk kelompok pembeli atau konsumen secara terpisah. Masing-masing segmen konsumen ini memiliki karakteristik, kebutuhan produk, dan bauran pemasaran tersendiri.

b. Targeting

Targeting adalah suatu tindakan memilih satu atau lebih segmen pasar yang akan dimasuki. 


\section{c. Positioning}

Positioning adalah penetapan posisi pasar. Tujuan positioning ini adalah untuk membangun dan mengkomunikasikan keunggulan bersaing produk yang ada di pasar kedalam benak konsumen.

\section{Strategi Pemasaran}

Menurut Kotler dalam Subing (2014). Strategi pemasaran adalah suatu wujud rencana yang terurai dibidang pemasaran. Untuk memperoleh hasil yang optimal, strategi pemasaran ini mempunyai ruang lingkup yang luas di bidang pemasaran diantaranya adalah strategi dalam menghadapi persaingan, strategi harga, strategi produk, strategi pelayanan dan sebagainya.

Menurut Andrew dalam Nizar (2016) strategi pemasaran adalah pola keputusan dalam perusahaan yang menentukan dan mengungkapkan sasaran, maksud atau tujuan yang menghasilkan kebijaksanaan utama dan merencanakan untuk pencapaian tujuan serta merinci jangkauan bisnis yang akan dikejar oleh perusahaan.

1. Product (produk) Produk merupakan elemen penting dalam sebuah program pemasaran. Strategi produk dapat mempengaruhi strategi pemasaran lainnya. Pembelian sebuah produk bukan hanya sekedar untuk memiliki produk tersebut tetapi juga untuk memenuhi kebutuhan dan keinginan konsumen.

2. Price (Harga) Harga merupakan pengorbanan ekonomis yang dilakukan pelanggan untuk memperoleh produk atau jasa. Selain itu harga salah satu faktor penting konsumen dalam mengambil keputusan untuk melakukan transaksi atau tidak.

3. Promotion (promosi) Promosi adalah kegiatan mengkomunikasikan informasi dari penjual kepada konsumen atau pihak lain dalam saluran penjualan untuk mempengaruhi sikap dan perilaku. Melalui periklanan suatu perusahaan mengarahkan komunikasi persuasif pada pembeli sasaran dan masyarakat melalui media-media yang disebut dengan media massa seperti koran, majalah, tabloid, radio, televisi dan direct mail. Media promosi yang dapat digunakan pada bisnis ini antara lain (1) periklanan, (2) promosi penjualan, (3) publisitas dan hubungan masyarakat, dan (4) pemasaran langsung. Penentuan media promosi yang akan digunakan didasarkan pada jenis dan bentuk produk itu sendiri. Suatu unsur yang digunakan untuk memberitahukan dan membujuk pasar tentang produk atau jasa yang baru pada perusahaan melalui iklan, 
penjualan pribadi, promosi penjualan maupun publikasi.

4. Place (Saluran Distribusi) Saluran distribusi terdiri dari seperangkat lembaga yang melakukan segala kegiatan (fungsi) yang digunakan untuk menyalurkan produk dan status pemiliknya dari produsen ke konsumen. Distribusi berkaitan dengan kemudahan memperoleh produk di pasar dan tersedia saat konsumen mencarinya.

5. People (Partisipan) Yang dimaksud partisipan disini adalah karyawan penyedia jasa layanan maupun penjualan, atau orang-orang yang terlibat secara langsung maupun tidak langsung dalam proses layanan itu sendiri,

6. Process (Proses) Proses adalah kegiatan yang menunjukkan bagaimana pelayanan diberikan kepada konsumen selama melakukan pembelian barang seperti pengelola klinik melalui front liner sering menawarkan berbagai macam bentuk pelayanan untuk tujuan menarik konsumen, fasilitas pengiriman produk, pembelian tiket, credit card, card member, dan fasilitas layaanan yang berpengaruh pada image perusahaan. Objektif utama dari pemasaran adalah mengidentifiasikan kebutuhan dan keinginan pasar.
7. Physical evidence (Lingkungan fisik) Fasilitas pendukung merupakan bagian dari pemasaran jasa yang memiliki peranan cukup penting. Karena jasa yang disampaikan kepada pelanggan tidak jarang memerlukan fasilitas pendukung di dalam penyampaian.

\section{Pengertian SWOT}

Menurut Rangkuti (2016:19)
Analisis SWOT adalah identifikasi
berbagai faktor secara sistematis untuk
merumuskan strategi perusahaan, analisis
ini didasarkan pada logika yang dapat
memaksimalkan kekuatan (Strenght) dan
peluang (Opportunities), namun secara
bersamaan dapat meminimalkan
kelemahan (Weakness) dan Ancaman
(Threats).

Menurut Suryatama dalam Puguh (2016) Analisis SWOT adalah metode perencanaan strategis yang digunakan untuk mengevaluasim kekuatan atau Strenghts, kelemahan atau Weaknesses, peluang atau Opportunities, dan ancaman Threast dalam suatu proyek atau suatu spekulasi bisnis. Dan dapat diterapkan dengan cara menganalisis dan memilah berbagai hal yang mempengaruhi keempat faktornya.

Analisis Internal meliputi :

1) Analisis Kekuatan (Strenghts) Strenght atau kekuatan adalah situasi atau kondisi yang merupakan kekuatan dari perusahaan. 
Strenght merupakan faktor internal yang mendukung perusahaan dalam mencapai tujuannya. Faktor pendukung dapat berupa teknologi, sumber daya, keahlian, kekuatan pemasaran, dan basis pelanggan yang dimiliki atau kelebihan lain yang mungkin diperoleh berkat sumber keuangan, citra, keunggulan dipasar, serta hubungan baik antara buyer dengan supplier.

2) Analisis Kelemahan (Weaknesses) Weaknesses atau kelemahan adalah kegiatan-kegiatan yang tidak berjalan dengan baik atau sumber daya yang dibutuhkan oleh perusahaan tetapi tidak dimiliki oleh perusahaan. Kelemahan itu terkadang lebih mudah dilihat dari pada sebuah kekuatan, namun ada beberapa hal yang menjadikan kelemahan itu tidak diberikan solusi yang tepat dikarenakan tidak dimaksimalkan kekuatan yang sudah ada. Weaknesses merupakan faktor internal yang menghambat perusahaan dalam mencapai tujuannya. Faktor penghambat dapat berupa fasilitas yang tidak lengkap, kurangnya sumber keuangan, kemampuan mengelola, keahlian pemasaran, dan citra perusahaan. Analisis Eksternal:

\section{1) Analisis Peluang (Opportunities)} Opportunities atau peluang adalah faktor positif yang muncul dari lingkungan dan memberikan kesempatan bagi perusahaan untuk memanfaatkannya. Opportunities merupakan faktor eksternal yang mendukung perusahaan dalam mencapai tujuannya. Faktor eksternal yang mendukung dalam pencapaian tujuan dapat berupa perubahan kebijakan, perubahan teknologi, perkembangan ekonomi dan perkembangan hubungan supplier dan buyer.

2) Analisis Ancaman (Threat) Threat atau ancaman adalah faktor negatif dari lingkungan yang memberikan hambatan bagi berkembangnya atau berjalannya sebuah perusahaan. Ancaman ini adalah hal yang terkadang selalu terlewatkan dikarenakan banyak yang ingin mencoba untuk kontroversi atau melawan arus. Namun, pada kenyataanya perusahaan tersebut lebih banyak layu sebelum berkembang. Threat merupakan faktor eksternal yang menghambat perusahaan dalam mencapai tujuannya. Faktor eksternal yang menghambat perusahaan dapat berupa masuknya pesaing baru, pertumbuhan pasar yang lambat, meningkatnya bergaining power dari pada supplier dan buyer utama, perubahan teknologi serta kebijakan baru. Menurut Suryatama dalam Puguh (2016)

\section{Pengertian Penjualan}

Menurut Thamrin Abdullah dan Francis Tantri (2016:3) Penjualan adalah bagian dari promosi dan promosi adalah 
salah satu bagian dari keseluruhan sistem pemasaran.

Menurut Leny Sulistiyowati (2010: mengartikan penjualan adalah"Pendapatan yang berasal dari penjualan produk perusahaan, disajikan setelah dikurangi potongan penjualan dan retur penjualan.

\section{Pengertian Pendapatan}

Menurut Nursandy dalam Wayan (2017) Pendapatan adalah seluruh penerimaan baik berupa uang maupun barang yang berasal dari pihak lain maupun dari hasil industri yang dinilai atas dasar jumlah uang dari harta yang berlalu saat itu. Pendapatan seseorang harus dapat digunakan untuk menentukan tingkat kesejahteraan sebab dengan pendapatan seseorang akan dapat memenuhi kebutuhan hidupnya sehari-hari baik secara langsung maupun tidak langsung. Definisi lain dari pendapatan adalah jumlah penghasilan yang diperoleh dari hasil pekerjaan dan biasanya pendapatan seseorang dihitung setiap tahun atau setiap bulan.

\section{METODE PENELITIAN}

\section{Jenis Penelitan}

Dalam Penelitian ini penulis menggunakan jenis penelitian kualitatif dengan pendekatan deskriptif yaitu sebuah penelitian yang bertujuan membuat pencandraan secara sistematis, factual dan akurat mengenai fakta-fakta dan sifat objek penelitian.

Statistik Deskriptif adalah statistic yang berfungsi untuk mendeskripsikan atau memberikan gambaran terhadap objek yang diteliti melalui data sampel atau populasi sebagaimana adanya, tanpa melakukan analisis dan membuat kesimpulan yang berlaku untuk umum.

Metode penelitian kualitatif adalah metodepenelitian yang berlandaskan filsafat positivisme, digunakan untuk meneliti pada kondisi objek yang alamiah, dimana peneliti adalah sebagai instrument kunci, pengambilan sampel sumber data dilakukan secara purposive dan snowball, teknikpengumpulan data dengan trianggulasi, analisis data bersifat induktif/kualitatif dan hasil penelitian lebih menekankan makna dari pada generalisasi. Sugiyono,(2015:19)

\section{Populasi dan Sampel}

1. Populasi

Populasi adalah wilayah generalisasi yang terdiri atas objek atau subyek yang mempunyai kualitas dan karakteristik tertentu yang diharapkan oleh bpeneliti untuk dipelajari dan kemudian ditarik kesimpulannya.

Jadi populasi bukan hanya orang, tetapi juga obyek dan benda-benda alam yang lain. Populasi juga bukan sekedar jumlah yang ada pada obyek subyek yang 
dipelajari, tetapi seluruh karakteristik atau sifat yang dimiliki oleh subyek atau obyek yang diteliti itu. (Sugiono 2015:80)

Dalam penelitian kualitatif sebenarnya tidak menggunakan istilah populasi tetapi dinamakan oleh situasi sosial yang terdiri dari tempat, perilaku dan aktivitas yang berinteraksi secara strategis. Populasi dalam penelitian ini adalah data dari seluruh kegiatan pada UKM Kacang Mede "Bawang Mas" Surabaya yang di dapat dari wawancara data manajemen usaha, pembeli dan pesaing.

\section{HASIL DAN PEMBAHASAN}

Tabel 1. Matriks IFAS (Internal Factors Analysis Summary)

\begin{tabular}{|l|l|l|c|}
\hline $\begin{array}{l}\text { FAKTOR- } \\
\text { FAKTOR } \\
\text { INTERNAL }\end{array}$ & $\begin{array}{l}\text { BOB } \\
\text { OT }\end{array}$ & $\begin{array}{l}\text { RATI } \\
\text { NG }\end{array}$ & $\begin{array}{c}\text { BOBO } \\
\text { T X } \\
\text { RATIN } \\
\text { G }\end{array}$ \\
\hline $\begin{array}{l}\text { KEKUATA } \\
\text { N }\end{array}$ & & \\
\hline $\begin{array}{l}\text { 1.Memiliki } \\
\text { prospek } \\
\text { usaha yang } \\
\text { baik }\end{array}$ & 0,14 & 4 & 0,56 \\
\hline $\begin{array}{l}\text { 2.Memiliki } \\
\text { pimpinan } \\
\text { yang } \\
\text { berjiwa } \\
\text { sosial dan } \\
\text { bertanggung } \\
\text { jawab. }\end{array}$ & 0,14 & 4 & 0,56 \\
\hline $\begin{array}{l}\text { 3.Memiliki } \\
\text { produk } \\
\text { yang } \\
\text { berdaya } \\
\text { saing tinggi } \\
\text { ( memiliki } \\
\text { keunikan } \\
\text { berupa seni } \\
\text { ukir } \\
\text { jeparaan) }\end{array}$ & 0,14 & 4 & 0,56 \\
\hline
\end{tabular}

\begin{tabular}{|c|c|c|c|}
\hline $\begin{array}{c}\text { FAKTOR- } \\
\text { FAKTOR } \\
\text { INTERNAL }\end{array}$ & $\begin{array}{l}\mathrm{BOB} \\
\mathrm{OT}\end{array}$ & $\begin{array}{l}\text { RATI } \\
\text { NG }\end{array}$ & $\begin{array}{l}\text { BOBO } \\
\text { T X } \\
\text { RATIN } \\
\quad \text { G }\end{array}$ \\
\hline $\begin{array}{l}\text { 4.Tersedian } \\
\text { ya peralatan } \\
\text { yang cukup } \\
\text { lengkap dan } \\
\text { modern. }\end{array}$ & 0,12 & 3 & 0,42 \\
\hline $\begin{array}{l}\text { SUB } \\
\text { TOTAL }\end{array}$ & 0,54 & & 2,1 \\
\hline \multicolumn{4}{|l|}{$\begin{array}{l}\text { KELEMAH } \\
\text { AN }\end{array}$} \\
\hline $\begin{array}{l}\text { 1. Letak } \\
\text { yang kurang } \\
\text { strategis }\end{array}$ & 0,12 & 3 & 0,36 \\
\hline $\begin{array}{l}\text { 2.Kurang } \\
\text { ramah } \\
\text { terhadap } \\
\text { lingkungan }\end{array}$ & 0,11 & 3 & 0,33 \\
\hline $\begin{array}{l}\text { 3.Kegiatan } \\
\text { promosi } \\
\text { belum } \\
\text { maksimal }\end{array}$ & 0,12 & 3 & 0,36 \\
\hline $\begin{array}{l}\text { 4.Jaringan } \\
\text { distribusi } \\
\text { yang belum } \\
\text { luas }\end{array}$ & 0,11 & 3 & 0,33 \\
\hline $\begin{array}{l}\text { SUB } \\
\text { TOTAL }\end{array}$ & 0,46 & & 1,38 \\
\hline TOTAL & 1 & & 3.48 \\
\hline
\end{tabular}

Sumber : Pengolahan data internal UD. Yoga Putra Bangkit

Pada matrik pembobotan atas faktor strategi internal (IFAS) pada tabel diatas skor total yaitu 3,48 yang dapat dikategorikan baik. Dikarenakan skor 3-4 sebagai nilai kondisi internal UD. Yoga Putra Bangkit adalah kuat. Berarti dapat dikatakan strategi internal kekuatan dan kelemahan yang dimiliki UD. Yoga Putra Bangkit di mungkinkan sebagai landasan perusahaan untuk melakukan rencana 
pertumbuhan dan perkembangan

perusahaan di masa depan.

Tabel 2. Matriks EFAS (External

Factors Analysis Summary)

\begin{tabular}{|c|l|l|c|}
\hline FAKTOR- & BOBOT & RATING & BOBOT X \\
FAKTOR & & & RATING \\
EKSTERN & & & \\
AL & & & \\
\hline
\end{tabular}

\begin{tabular}{|l|l|l|c|}
\hline \multicolumn{2}{|l|}{ PELUANG } \\
\hline $\begin{array}{l}\text { 1. Terdapat } \\
\text { berbagai } \\
\text { media sosial } \\
\text { yang dapat } \\
\text { digunakan } \\
\text { sebagai } \\
\text { media iklan. }\end{array}$ & 0,21 & 4 & 0,84 \\
\hline $\begin{array}{l}\text { 2.Ketersidia } \\
\text { an bahan } \\
\text { baku yang } \\
\text { cukup. }\end{array}$ & 0,22 & 4 & 0,88 \\
\hline $\begin{array}{l}\text { 3.Tersedian } \\
\text { ya pasar } \\
\text { furniture } \\
\text { yang selalu } \\
\text { berkembang }\end{array}$ & 0,18 & 3 & 0,54 \\
\hline $\begin{array}{l}\text { SUB } \\
\text { TOTAL }\end{array}$ & 0,61 & & \\
\hline
\end{tabular}

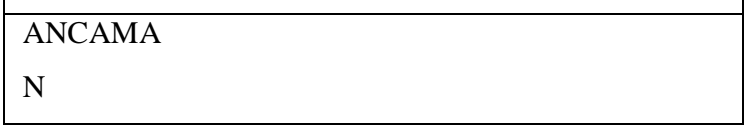

\begin{tabular}{|l|c|c|c|}
\hline $\begin{array}{l}\text { 1. Tingkat } \\
\text { daya beli } \\
\text { masyarakat } \\
\text { yang } \\
\text { rendah. }\end{array}$ & 0,8 & 1 & 0,8 \\
\hline $\begin{array}{l}\text { 2.Banyak } \\
\text { beredar } \\
\text { produk } \\
\text { sejenis dari } \\
\text { pesaing. }\end{array}$ & 0,12 & 1 & 0,12 \\
\hline $\begin{array}{l}\text { 3.Semakin } \\
\text { meningkatn } \\
\text { ya produk }\end{array}$ & 0,11 & 1 & 0,11 \\
\hline
\end{tabular}

\begin{tabular}{|l|c|c|c|}
\hline $\begin{array}{c}\text { FAKTOR- } \\
\text { FAKTOR } \\
\text { EKSTERN } \\
\text { AL }\end{array}$ & BOBOT & RATING & $\begin{array}{c}\text { BOBOT X } \\
\text { RATING }\end{array}$ \\
\hline subtitusi. & & 1 & 0,08 \\
\hline $\begin{array}{l}\text { 4.Maraknya } \\
\text { pesaing } \\
\text { baru. }\end{array}$ & 0,08 & 1 & 0,39 \\
\hline $\begin{array}{l}\text { SUB } \\
\text { TOTAL }\end{array}$ & 0,39 & & 2,65 \\
\hline TOTAL & 1 & & \\
\hline
\end{tabular}

Sumber : Pengolahan data internal UD. Yoga Putra Bangkit

Dari tabel matrik EFAS, dapat disimpulkan bahwa UD. Yoga Putra Bangkit sudah bisa memanfaatkan peluang yaitu Terdapat berbagai media sosial yang dapat digunakan sebagai media iklan, Ketersidiaan bahan baku yang cukup, Tersedianya pasar furniture yang selalu berkembang. Untuk menutupi faktor-faktor yang menjadi ancaman. Hal ini dapat dilihat dengan lebih besarnya sekor peluang yaitu 2,26 dibandingkan faktor ancaman yang hanya 0,39 sehingga total nilai EFAS 2,62.

Tabel 3 hasil analisis faktor internal (IFAS) dan faktor eksternal (EFAS), diperoleh nilai skor sebagai berikut:

\begin{tabular}{|c|c|c|c|}
\hline $\begin{array}{c}\text { Kekuatan } \\
\text { (strenght) }\end{array}$ & $\begin{array}{c}\text { Kelemahan } \\
\text { (weakneass) }\end{array}$ & $\begin{array}{c}\text { Peluang } \\
\text { (opportunity) }\end{array}$ & $\begin{array}{c}\text { Ancaman } \\
\text { (threats) }\end{array}$ \\
\hline 2,1 & 1,38 & 2,26 & 0,39 \\
\hline \multicolumn{2}{|c|}{ Sumbu Y = kekuatan -} & \multicolumn{2}{|c|}{$\begin{array}{r}\text { Sumbu X }=\text { peluang }- \\
\text { ancaman }\end{array}$} \\
kelemahan & \multicolumn{2}{|c}{$=2,26-$} \\
$=0,72$ & 0,39 \\
& & $=1,87$ \\
\hline
\end{tabular}

Dari identifikasi faktor-faktor tersebut maka dapat digambarkan diagram 


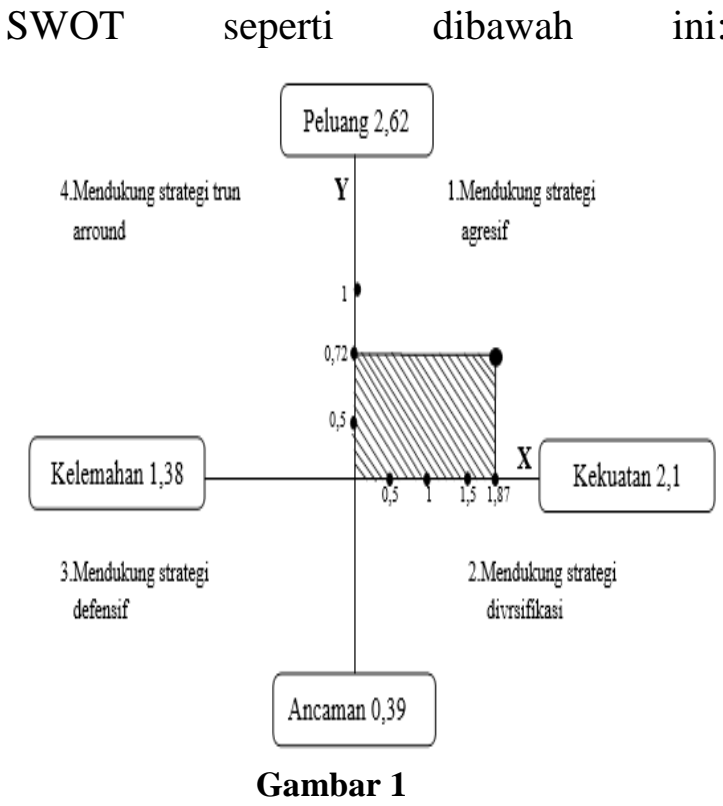

Analisis Diagram SWOT

\section{KESIMPULAN}

Analisis strategi pemasaran dengan menggunakan analisis SWOT dapat meningkatan penjualan dan pendapatan pada UD. Yoga Putra Bangkit hal ini dapat diketahui dari hasil analisis SWOT skor kekuatan (strenght) 2,1, Kelemahan (weakness) 1,38, peluang (opportunity) 2,26 dan ancaman (threat) 0,39. Dari diagram SWOT diatas, dapat dapat dinilai dari selisih nilai skor kekuatan dan kelemahan, nilai skor keuatan lebih tinggi dengan selisih 0,72. Sedangkan nilai skor peluang dengan ancaman lebih tinggi peluang dengan selisih 1,87 , sehingga dengan jelas menunjukkan bahwa UD. Yoga Putra Bangkit pada saat ini ada pada kuadran merupakan situasi yang sangat menguntungkan. UD.Yoga Putra Bangkit memiliki peluang dan kekuatan sehingga dapat memanfaatkan peluang yang ada. Strategi yang harus ditetapkan dalam kondisi ini adalah mendukung kebijakan pertumbuhan yang agresif. Dengan melakukan strategi agresif UD. Yoga Putra Bangkit akan mampu bersaing dan meningkatkan penjualan dan pendapatan.

Strategi yang bisa diterapkan UD. Yoga Putra Bangkit dalam meningkatkan penjualan dan pendapatan adalah strategi SO, WO, ST, WTyaitu dengan tetap konsisten dalam menjaga kualitas produk dengan menggunkan bahan baku yang kualitas baik (kayujati asli dengan izin yang resmi), Memanfaatkan bahan baku yang cukup tersedia dan peralatan yang modern dan menghasilkan produk yang bervariasi, memanfaatkan berbagai media sosial untuk kegiatan promosi agar menarik daya beli masyakat, meminimalisir dampak dari proses produksi, terus melakukan inovasi dan meningkatkan kualitas produk guna mengungguli persaingan antara perusahaan sejenis, lebih menonjolkan seni jeparaan, konsisten memberikan pelayanan yang memuaskan kepada konsumen, melakukan perbaikan pada kelemahan yang ada.

\section{DAFTAR PUSTAKA}

Abdullah, Thamrin dan Francis Tantri. 2016. Manajemen Pemasaran. PT. Raja Grafindo Persada. Depok.

Anogara Pandji.2011. Pengantar Bisnis. Rineka Cipta, Jakarta.

Cahyono, Puguh. 2016. Implementasi Strategi Pemasaran dengan Menggunakan Metode SWOT dalam Upaya Meningkatkan Penjualan Produk Asuransi Kecelakaan dan Kematian pada PT. Prudential Cabang Lamongan. Jurnal Penelitian Ilmu Manajemen. Volume 1(2); 2502-3780.

Mukhtar. 2013. Metode Penelitian Deskriptif Kualitatif. GP Press Group, Jakarta.

Mumpuni, Diyah. 2013. Analisis Strategi SWOT untuk Meningkatkan Volume Penjualan pada Perusahaan MIE SOUN Gelang Indah Cilacap. Jurnal Dyah Analisis Strategi SWOT. Volume 2(3); 175-182.

Nuary, Nizar Sapta. 2016. Strategi Pemasaran dengan Pendekatan Analisis SWOT pada PT. Super Sukses Motor Banjarmasin. Jurnal Ilmiah Ekonomi Bisnis. Volume 2(1); 30-42.

Rohmah, Eli Lailatur. 2015. Strategi Manajemen Pemasaran dengan 
Pendekatan Analisis SWOT untuk Meningkatkan Volume Penjualan pada Pabrik Air Kemasan KSU Kencana Makmur Sugihan Solokuro Lamongan. Skripsi. Universitas Islam Lamongan.

Rangkuti, Freddy. 2016. Teknik Membedah Kasus Bisnis Analisis SWOT. Gramedia, Jakarta.

Subing, H.Achmad, dan Ferdian Dwi Saputra. 2014. Analisis Strategi Pemasaran Untuk Meningkatkan Penjualan Motor Merk Mio J Cw FI Pada PT. Bahana Pagar Alam Di Bandar Lampung. Jurnal Manajemen dan Bisnis. Volume 4(2); 197-220.

Sugiyono. 2016. Metode Penelitian. Kusntitatif, Kualitatif, dan $R \& D$. Alfabeta, Bandung.

Sulistyawati, leny. 2010. Pemanduan praktis Memahami Analisis laporan Keuangan. PT. Elex Media Kompitundo. Jakarta.

Wijaya,Wayan, Yulianeu, Tsalis Syaifuddin, Heri Sri Wulan. 2017. Strategi Pengembangan Usaha CV.Steba Adevtaising Semarang dalam Meningkatkan Pendapatan. Jurnal of Management. Volume 3(3) 
